\title{
Prevalence of bovine trypanosomosis in Ethiopia: a meta-analysis
}

Samson Leta ${ }^{1 *}$, Gezahegn Alemayehu², Zewdu Seyoum $^{1}$ and Melkamu Bezie ${ }^{1}$

\begin{abstract}
Background: Trypanosomosis is a haemoprotozoan disease, mostly transmitted by the tsetse fly (Glossina spp.), it causes severe disease in humans and animals in Sub-Saharan Africa (SSA). The disease results in loss of livestock and agricultural productivity with severe socio-economic impacts. In Ethiopia, bovine trypanosomosis is widely distributed in western and south-western parts of the country. It is estimated that some 10 to 14 million heads of cattle in Ethiopia are exposed to the risk of trypanosomosis.

Methods: This study describes the prevalence of bovine trypanosomosis in Ethiopia through a meta-analysis. A comprehensive search was conducted on PubMed and non-PubMed indexed articles were also incorporated based on expert suggestion. Eligible studies were selected by using inclusion and exclusion criteria. Pooled prevalence was estimated by random effect model. Publication bias and the variation in prevalence estimates attributed to heterogeneity were also assessed.

Results: Twenty-four studies with relevant prevalence data were identified and included in the analysis. The apparent prevalence of bovine trypanosomosis varied from 1.38 to $17.15 \%$. The pooled estimate of bovine trypanosomosis prevalence across studies for the entire period was $8.12 \%$ (95 \% Cl: 6.88; 9.35), ranging from $10.27 \%(95 \%$ Cl: $7.34 ;$ 13.20) in the late 1990s and early 2000s, to $6.81 \%$ (95 \% Cl: 5.00; 8.62) after 2010. Sub-analysis by region revealed wide variations in prevalence. The highest estimated regional prevalence was $13.30 \%$ (95 \% Cl: 7.73; 18.88) in Benishangul Gumuz Regional state. A high degree of heterogeneity was observed in most pooled estimates and even after sub-group analysis. The visual inspection of the funnel plot and the Egger's regression asymmetry coefficient $[b=2.18](95 \% \mathrm{Cl}=-1.09,5.46 ; p>0.05)$ did not suggest the presence of publication bias. T. congolense and T. vivax were reported to be the predominant causative agents. From the total positive animals, 45.5 and $44.3 \%$ of the infections are accounted to T. congolense and T. vivax, respectively.

Conclusions: The meta-analysis showed a significant reduction in prevalence of bovine trypanosomosis in recent years, but the reduction is not to the lowest necessary level. Since $T$. vivax is reported to be one of the most important trypanosome species involved, efforts should also be made to control the mechanical transmission by biting flies.
\end{abstract}

Keywords: Bovine trypanosomosis, Ethiopia, Meta-analysis, Prevalence

\footnotetext{
* Correspondence: samiwude@gmail.com

${ }^{1}$ Faculty of Veterinary Medicine, University of Gondar, P.O. Box: 196, Gondar,

Ethiopia

Full list of author information is available at the end of the article
} 


\section{Background}

According to the Food and Agricultural Organization of the United Nations, trypanosomosis is probably the only disease which has a significant effect on the settlement and socio-economic development of a major part of SSA. Of the approximately 7-10 million $\mathrm{km}^{2}$ of land that are infested by tsetse fly only 20 million cattle are reared. If it is free from tsetse and trypanososmosis, this land could support more than 140 million heads of cattle and increase meat production by 1.5 million tons [1]. Bovine trypanosomosis causes about 3 million deaths every year and approximately 35 million doses of trypanocidal drugs are being administered every year to enable livestock to survive in tsetse-infested areas. While the economic losses in cattle production alone is up to US $\$ 1.2$ billion, the indirect impact engendered by the disease on the agriculture-livestock production is estimated to be about US $\$ 4.5$ billion a year [2]. The overall negative impact of trypanosomosis extends to the access and availability of cultivable areas, changes in land use and exploitation of natural resources, restriction of opportunities for agricultural diversification and intensification.

Trypanosomosis directly affects the milk and meat productivity of animals, reduces birth rates, increases abortion as well as mortality rates; all of these reduce the herd size and herd composition. The indirect impact of the disease mostly lies on crop production through the availability and cost of animals that provide traction power [3]. Trypanosomosis reduces work efficiency of oxen and discourages the introduction of drought animals in to crop farming [4]. Shaw et al. [5] discussed the economic benefits from intervening against bovine trypanosomosis. These authors reported significant benefits especially for Ethiopia, because of its very high livestock densities and the importance of animal traction. The estimated maximum benefit per square kilometer of tsetse infested area over a 20 year period is US $\$ 10,000$. Consequently, the total maximum benefits from dealing with bovine trypanosomosis in Ethiopia could be as much as US $\$ 1$ billion over a 20 year period.

In Ethiopia, significantly large numbers of works have been conducted to determine the prevalence of bovine trypanosomosis. However, the studies were limited in spatial scope and the results significantly vary between the studies. In this study, we used previously conducted studies to determine the overall prevalence of bovine trypanosomosis using meta-analysis. Disease control and prevention should be based on transparent and evidence-based planning. Unfortunately, the information in the literature is often inconclusive and could be conflicting. Meta-analysis has been defined as: "The statistical analysis of a large collection of analysis results from individual studies for the purpose of integrating the findings" [6]. It is a formal process for combining results from a number of studies that is being used increasingly in human medicine and, to a more limited extent, in veterinary medicine. A more complete description of meta-analyses can be found in $[7,8]$.

Therefore, the objective of this study was to estimate the overall prevalence of bovine trypanosomosis in Ethiopia based on data from a number of scientific studies.

\section{Methods}

The study was conducted based on the guideline of the Preferred Reporting Items for Systematic Reviews and Meta Analyses the (PRISMA) group checklist [9]. The checklist was used to ensure inclusion of relevant information (Additional file 1). The outcome of interest was the proportions of cattle infected with different species of trypanosomes.

\section{Study area}

The study was conducted in Ethiopia; a country situated in the horn of Africa located between $3^{\circ} 00^{\prime}-15^{\circ} 00^{\prime} \mathrm{N}$ latitude and $32^{\circ} 30^{\prime}-48^{\circ} 00^{\prime} \mathrm{E}$ longitude. It covers a land area of 1.04 million $\mathrm{km}^{2}$. With a population of 94.10 million, Ethiopia is the second most populous nation in Africa following Nigeria [10]. Ethiopia is suitable for agricultural production and it is also a home for an estimated 54, 25.5 and 24 million heads of cattle, sheep and goat, respectively [11].

The country has a diverse topography, which forms the basis for several agro-climatic zones. The area above $2300 \mathrm{~m}$ above sea level (m.a.s.l.) is considered highland, which is surrounded by a temperate transition zone between 1500 and 2300 m.a.s.l. Areas having an altitude below 1500 m.a.s.l. are classified as lowlands.

\section{Literature search and eligibility criteria}

Comprehensive literature searches were conducted on PubMed (covering all dates from the creation of each database up to November 29, 2015). Ethiopian experts in the field were contacted to suggest other potential articles which were published in non-PubMed indexed journals. The following $\mathrm{MeSH}$ terms were used in electronic database search: "Trypanosomiasis", "Trypanosomosis", "Bovine trypanosomosis", "Bovine trypanosomiasis", "Prevalence of bovine trypanosomosis", "Prevalence of bovine trypanosomiasis" and "Ethiopia". Systematic reviews of available literature were performed to identify relevant publications about the prevalence of bovine trypanosomosis in Ethiopia. First, titles and abstracts were assessed, and respective papers were examined in detail. To be eligible, the following inclusion criteria were used: a study had to be (i) published in a reputable journal, (ii) written in English, (iii) crosssectional study and (iv) conducted in Ethiopia (v) number 
of infected animals, size of study population and test method available (vi) published as of 2000 . Mendeley version 1.15.2 was used to catalogue the initial literature search results and to manage citations.

\section{Data extraction}

From eligible studies, the following data were extracted: the first author, year of publication, year of study, study design, location, sampling design, sample size, test methods and prevalence. Prevalence of trypanosomosis was defined as the frequency of cases by $T$. congolense, T. vivax and/or $T$. brucei infection in a given population at a given period of time. The study level estimates and confidence intervals were derived from the extracted data.

\section{Data synthesis and analysis}

Data analysis was carried out in different steps. First, mean prevalence was calculated, using the sum of the numbers of cases in all studies considered, divided by the sum of the number of cattle sampled. The $95 \%$ confidence interval ( $95 \% \mathrm{CI}$ ) was computed using exact binomial method. If the study did not report the year of data collection, the preceding year of the year of publication was considered. The pooled prevalence estimates for bovine trypanosomosis in the general population and their $95 \%$ CI were calculated using the random-effects model meta-analysis [12].

Heterogeneity between studies was evaluated through the Cochran's Q test (reported as $p$ value) and inverse variance index $\left(I^{2}\right)$, which describes the percentage of observed total variation between studies that are due to heterogeneity rather than chance. The $I^{2}$ values of 25 , 50, and $75 \%$ show low, moderate, and high degrees of heterogeneity, respectively. The $I^{2}$ values $0 \%$ indicate no observed heterogeneity. $\mathrm{Q}$ is the weighted of squares on a standardized scale. It is reported with a $p$ value with low $p$ values indicating the presence of heterogeneity [13].

Sub-group analyses were performed to determine the potential sources of heterogeneity among studies. The variables included in the sub-group analysis were: study area (region), sample size and year of the study.

The across study bias was first visually examined by a funnel plot, and then Egger's regression asymmetry test was used to test the statistical significance of the bias [14]. The unbiased estimates were calculated using Duval and Tweedie non-parametric 'fill and trim' linear random method [15].

For each study, the prevalence with corresponding $95 \% \mathrm{CI}$ and the overall random-effects pooled estimate of all the studies were presented.

Data were analysed using Stata software version 12 (StataCorporation, College Station, USA) and Comprehensive Meta-Analysis software version 3.3.070 (Biostat, Englewood, USA). A map detailing the prevalences at study sites was created, using Quantum GIS software version 2.0.1 (Open Source Geospatial Foundation, Boston, USA).

\section{Result}

\section{Literature search results}

Of 408 studies identified through electronic search and 5 studies suggested by the experts, 24 were considered for the meta-analysis [16-39]. Figure 1 the flow diagram of eligible study selection. These included a total of 27,719 cattle, with 2,274 cases. T. congolense and $T$. vivax were the predominant cause of the infection. From the total positive animals 45.5 and $44.3 \%$ of them accounted to $T$. congolense and $T$. vivax, respectively and the remaining accounted to T. brucei.

\section{Characteristics of the studies}

The studies were conducted between 1997 and 2014 in 6 regional states, namely Afar, Amhara, Beneshangul Gumuz, Oromia, South Nations Nationalities and Peoples Region (SNNPR) and Tigray. The sample size ranged from 250 to 7,079 cattle (mean: 1155; standard deviation $[\mathrm{SD} \pm]$ : 1525). In all the studies Haematocrit centrifugation technique (HCT) was used for the diagnosis of the infection. The apparent prevalence of bovine trypanosomosis varied from 1.38 to $17.15 \%$ (mean: 8.28; standard deviation $[\mathrm{SD} \pm]$ : 3.64 ). Detailed characteristics of the studies included are presented in Table 1.

\section{Geographical distribution of study sites}

A total of 49 survey districts were identified from the 24 studies; however, five sites were not included into the map due to lack of unique location identifier. Spatial distribution and observed prevalence (size of the point is proportional to the prevalence) by location are depicted in Fig. 2. Most studies were performed in the western and south-western parts of the country. Some states, namely Amhara, Benishanguz Gumuz, Oromia and SNNPR contain a large number of survey locations, while other states, namely Afar and Tigray have only a few disease surveys published. The mean apparent prevalence ranged between states, Amhara $8.17 \%$, Benishangul Gumuz $13.86 \%$, Oromia $6.34 \%$ and SNNPR $7.91 \%$. An overview of the identified survey districts with disease prevalence data is provided as Additional file 1.

\section{Meta-analysis and meta-regression}

Pooled prevalence estimates for the 24 studies included in the meta-analysis are presented in Table 2. Substantial heterogeneity was observed in the pooled estimate, which remained even after sub-group analysis. The pooled estimate of bovine trypanosomosis across studies for the entire period was $8.12 \%$ (95 \% CI: 6.88-9.35), ranging from 10.27 \% (95 \% CI: 7.34-13.20) in the late 1990s and 


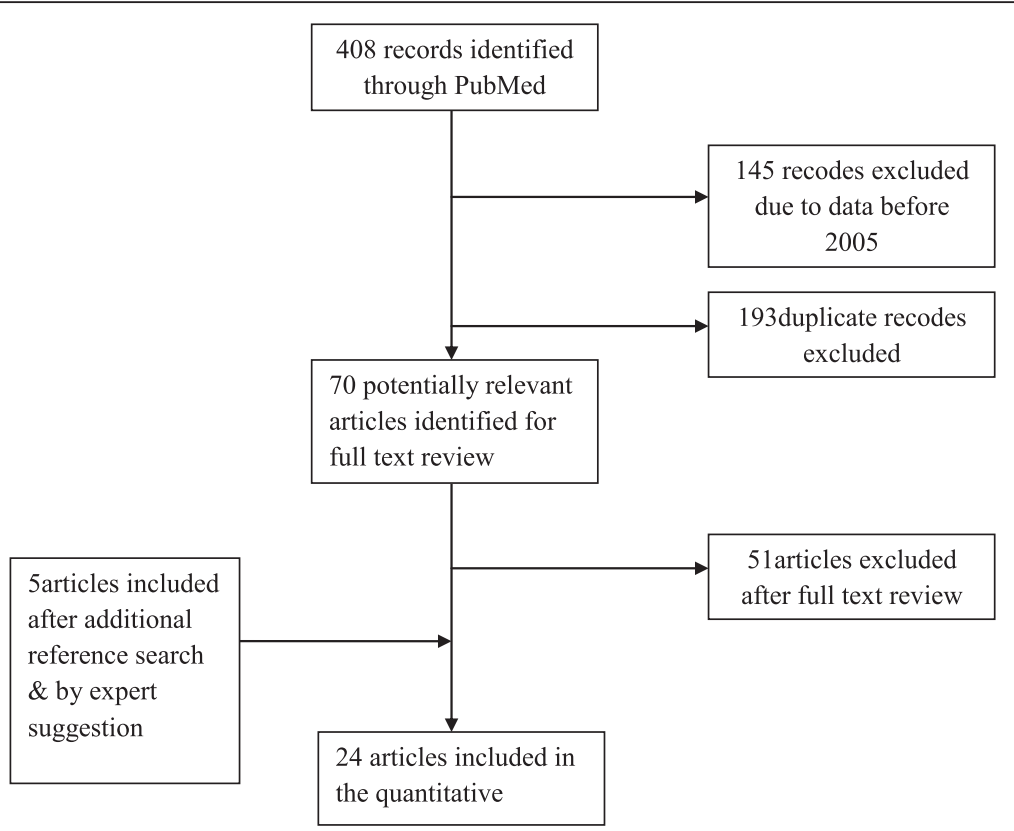

Fig. 1 Flow diagram of the selection of eligible studies

Table 1 A list of the studies included in the meta-analysis

\begin{tabular}{|c|c|c|c|c|}
\hline Author (year) & Study year & Sample size & No. positive & Apparent prevalence \\
\hline Sheferaw et al. 2015 [32] & 2014 & 1838 & 133 & 7.24 \\
\hline Birhanu et al. 2015 [19] & 2013 & 493 & 36 & 7.30 \\
\hline Lelisa et al. 2015 [28] & 2014 & 405 & 22 & 5.43 \\
\hline Terefe et al. 2015 [36] & 2014 & 409 & 25 & 6.11 \\
\hline Abera et al. 2014 [16] & 2014 & 384 & 24 & 6.25 \\
\hline Biyazen et al. 2014 [21] & 2014 & 384 & 11 & 2.86 \\
\hline Lelisa et al. 2014 [27] & 2010 & 389 & 42 & 10.80 \\
\hline Tamiru et al. 2014 [35] & 2013 & 436 & 6 & 1.38 \\
\hline Tafese et al. 2012 [34] & 2011 & 386 & 33 & 8.55 \\
\hline Tesfaye et al. 2012 [37] & 2009 & 1260 & 153 & 12.14 \\
\hline Fikru et al. 2012 [24] & 2011 & 1524 & 81 & 5.31 \\
\hline Bishaw et al. 2012 [20] & 2011 & 384 & 30 & 7.81 \\
\hline Bekele \& Nasir, 2011 [18] & 2011 & 384 & 33 & 8.60 \\
\hline Mekuria \& Gadissa, 2011 [29] & 2009 & 540 & 67 & 12.41 \\
\hline Dagnachew \& Shibeshi, 2011 [23] & 2009 & 368 & 33 & 8.97 \\
\hline Tadesse \& Tsegaye, 2010 [33] & 2009 & 250 & 11 & 4.40 \\
\hline Kebede \& Animut, 200939 & 2008 & 3200 & 322 & 10.06 \\
\hline Miruk et al. 200831 & 2007 & 341 & 40 & 11.73 \\
\hline Mihret \& Mamo, 200730 & 2005 & 3360 & 275 & 8.20 \\
\hline Sinshaw et al. 2006 [48] & 2004 & 1509 & 92 & 6.10 \\
\hline Cherenet et al. 200422 & 2001 & 7079 & 501 & 7.08 \\
\hline Tewelde et al. 200438 & 2001 & 904 & 70 & 7.74 \\
\hline Kidanemariam et al. 200226 & 2001 & 1008 & 151 & 14.98 \\
\hline Afewerk et al. 200017 & 1997 & 484 & 83 & 17.15 \\
\hline
\end{tabular}




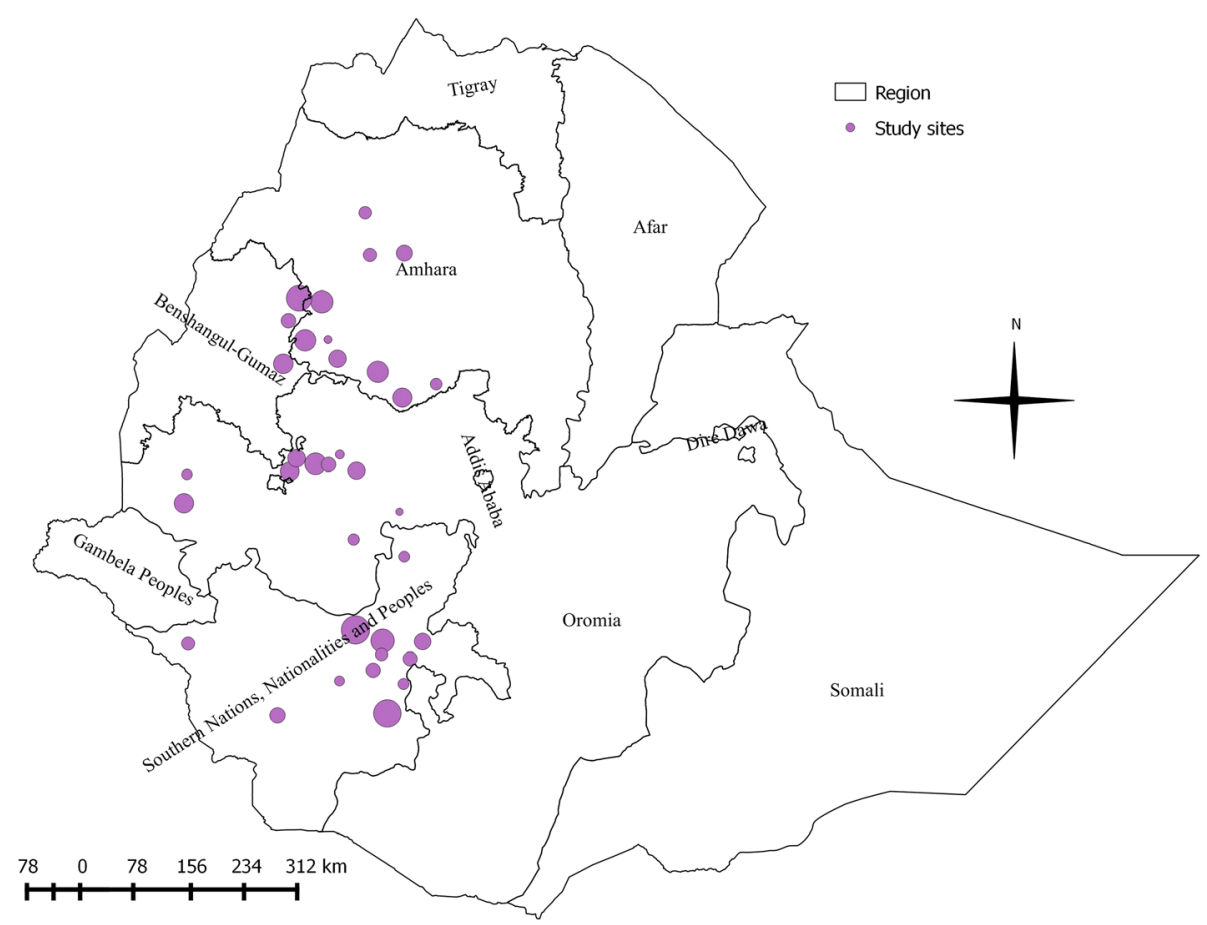

Fig. 2 Observed spatial distribution of bovine trypanosomosis in Ethiopia

early 2000s, to $6.81 \%$ (95 \% CI: 5.00-8.62) after 2010 . Factors that could explain some of this variance were tested in the subsequent meta-regression. Results with coefficients, $p$ values and Cochran's Q Statistics from the univariable meta-regression analyses are outlined in
Table 3. Region and survey year had a univariable $p$ value $<0.05$, indicating a time-space stable pattern. A meta-regression of bovine trypanosomosis by survey year (consider here as a continuous variable) indicated a significant reduction in the prevalence of bovine

Table 2 Pooled prevalence estimates of bovine trypanosomosis, stratified by sub-groups

\begin{tabular}{|c|c|c|c|c|c|c|c|}
\hline \multirow[t]{2}{*}{ Characteristics } & \multirow{2}{*}{$\begin{array}{l}\text { Number of } \\
\text { studies }\end{array}$} & \multicolumn{4}{|c|}{ Pooled bovine trypanosomosis prevalence } & \multicolumn{2}{|c|}{ Heterogeneity } \\
\hline & & Sample size & Cases & Prevalence (\%) & $95 \% \mathrm{Cl}$ & $P \%$ & P-value (Cochran's Q) \\
\hline Overall prevalence & 24 & 27,719 & 2274 & 8.12 & $6.88-9.35$ & 93.1 & 0.000 \\
\hline \multicolumn{8}{|l|}{ Region } \\
\hline Afar & 1 & 82 & 4 & 4.88 & $0.19-9.57$ & 0.00 & 1.00 \\
\hline Amhara & 6 & 15,937 & 1263 & 8.05 & $6.79-9.31$ & 85.09 & 0.000 \\
\hline Benishangul Gumuz & 4 & 2284 & 286 & 13.30 & $7.73-18.88$ & 93.56 & 0.000 \\
\hline Oromia & 8 & 2943 & 189 & 6.18 & $3.63-8.72$ & 91.02 & 0.000 \\
\hline SNNPR & 6 & 4045 & 366 & 7.87 & $4.56-11.19$ & 92.93 & 0.000 \\
\hline Tigray & 1 & 411 & 32 & 7.79 & 5.19-10.39 & 0.00 & 1.00 \\
\hline \multicolumn{8}{|l|}{ Survey year } \\
\hline 1997-2004 & 5 & 10,984 & 897 & 10.27 & 7.34-13.20 & 95.17 & 0.000 \\
\hline 2005-2009 & 6 & 8059 & 1045 & 9.17 & $7.41-10.93$ & 81.85 & 0.000 \\
\hline 2010-2015 & 13 & 8676 & 332 & 6.81 & $5.00-8.62$ & 92.18 & 0.000 \\
\hline \multicolumn{8}{|l|}{ Sample size } \\
\hline$<384$ & 3 & 959 & 84 & 8.25 & $3.99-12.51$ & 84.01 & 0.002 \\
\hline $384-1000$ & 8 & 5982 & 482 & 8.72 & $7.16-10.29$ & 93.96 & 0.000 \\
\hline$\geq 1000$ & 13 & 20,778 & 1708 & 7.74 & $5.49-9.98$ & 92.78 & 0.000 \\
\hline
\end{tabular}


Table 3 Regression coefficients, $p$ values and Cochran's Q statistics from univariate meta-regression of bovine trypanosomosis in Ethiopia

\begin{tabular}{|c|c|c|c|c|c|}
\hline Variable & Category & Number & Coefficient & $p$ value & Cochran's Q statistics \\
\hline \multirow[t]{6}{*}{ Region } & Benishangul Gumuz & 2284 & Reference & & $\mathrm{Q}=11.58, \mathrm{df}=5, p=0.041$ \\
\hline & Afar & 82 & -7.67 & 0.056 & \\
\hline & Amhara & 15,937 & -4.42 & 0.029 & \\
\hline & Oromia & 2943 & -6.45 & 0.001 & \\
\hline & SNNPR & 4045 & -4.70 & 0.022 & \\
\hline & Tigray & 411 & -4.76 & 0.172 & \\
\hline \multirow[t]{3}{*}{ Survey year } & 1997-2004 & 10,984 & Reference & & $\mathrm{Q}=7.33, \mathrm{df}=2, p=0.026$ \\
\hline & $2005-2009$ & 8059 & -1.28 & 0.432 & \\
\hline & 2010-2015 & 8676 & -4.13 & 0.013 & \\
\hline \multirow[t]{3}{*}{ Sample size } & $<384$ & 959 & Reference & & $\mathrm{Q}=0.75, \mathrm{df}=2, p=0.686$ \\
\hline & $384-<1000$ & 5982 & -0.59 & 0.774 & \\
\hline & $>1000$ & 20,778 & 0.57 & 0.786 & \\
\hline
\end{tabular}

trypanosomosis $(b=-0.51 ; 95 \% \mathrm{CI}=-0.80 ;-0.23 ; p<$ $0.05)$. The scatterplot of regression of mean prevalence on year of study is presented in Fig. 3. Sub-group analysis by region revealed wide variations in prevalence. The highest estimated regional prevalence was $13.30 \%$ (95 \% CI: 7.73-18.88) in Benishangul Gumuz Regional state (Table 2) and was chosen as reference in the meta-regression. Compared to Benishangul Gumuz Regional State, Amhara, Oromia and SNNPR had significantly lower prevalence $(p<0.05)$ as shown in Table 3 . Region, survey year and sample size explained 18, 5.5 and $2.7 \%$ of the between study variance, respectively.

\section{Publication bias}

The funnel plots (Fig. 4) and the Egger's regression asymmetry coefficient $[b=2.18](95 \% \mathrm{CI}=-1.09$, 5.46; $p>0.05)$ did not suggest the presence of publication bias, and no theoretical missing study was incorporated by the Duval and Tweedie'strim and fill method.

\section{Discussion}

This study presents the first systematic nationwide analysis of bovine trypanosomosis prevalence in Ethiopia. It describes the prevalence estimates in Ethiopia derived from scientific reports. Bovine trypanosomosis

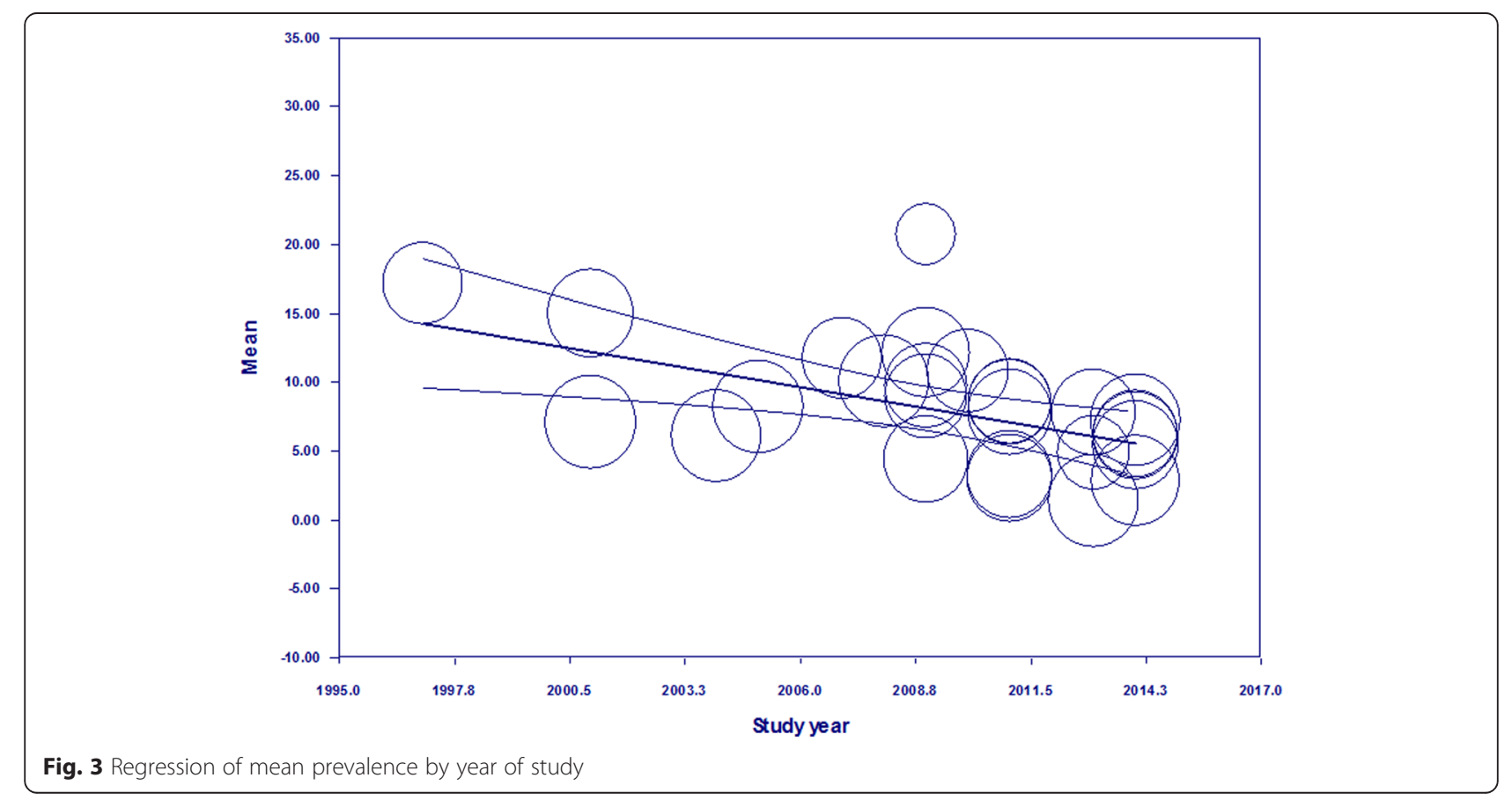




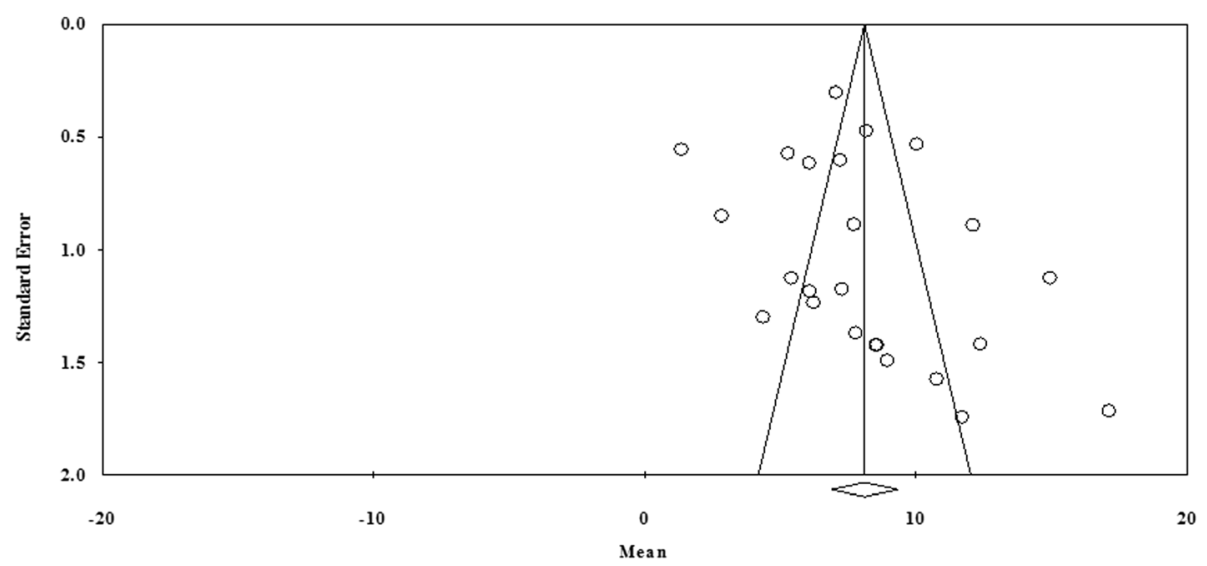

Fig. 4 Funnel plots of the standard error by mean prevalence estimates

prevalence varied over time, with lowest levels since 2010. Previous and on-going tsetse control activities in the affected areas of Ethiopia could be the reason for the decrement in the prevalence of bovine trypanosomosis. Significant variations have been observed in the prevalence of bovine trypanosomosis among regions. The variation between states would seem to indicate differences in effort and attitudes to tsetse and trypanosomosis control and eradication. The prevalence is significantly higher in Benishangul Gumuz Regional state, which is considerable remote with little tsetse control effort. The Ethiopian government, Pan-African Tsetse Eradication Campaign (PATEC) and International Atomic Energy Agency (IAEA) have been making a considerable effort to suppress tsetse fly challenge especially in Oromia, Amhara and SNNPR regions. Deltamethrin impregnated targets and Deltamethrin pour-on formulation have been widely used in Ethiopia to reduce tsetse challenge and the impact of trypanosomosis. However, In SNNPR, the Ethiopian government in association with IAEA have been using the sterile insect technique (SIT) to eradicate tsetse and reports indicate a significant reduction in tsetse and trypanosomosis challenge. The joint project between Ethiopian government and IAEA, Southern Tsetse Eradication Project (STEP), aimed to suppress tsetse from an estimated 25,000 $\mathrm{km}^{2}$. According to Gechere et al. [40], the fly density, trypanosomosis prevalence and mortality due to trypanosomosis have been significantly reduced in the project area. Additionally, the government of Ethiopia has conducted a massive settlement program in early 2000s to the tsetse and trypanosomosis belt. So, the destruction of the tsetse habitat by the settlers believed to lend a hand to the tsetse and trypanosomosis control programs in reducing the potential tsetse suitable areas.

The distribution of bovine trypanosomosis is found to be widespread covering most parts of the western and south-western parts of the country. This area is long known to be the major tsetse and trypanosomosis belt in Ethiopia [41, 42]. The area is one of the wettest and agriculturally productive parts of the country. Estimates made decades ago reported that 180,000-220,000 $\mathrm{km}^{2}$ land in the western and south western parts of the country to be suitable for tsetse, the biological vector of trypanosomosis. A recent estimate made by Leta et al. [43] reported that $140,000 \mathrm{~km}^{2}$ of fertile agricultural land which is roughly $12 \%$ of the country's landmass is found to be a suitable habitat for tsetse. However, it is important to note that the comparison between previous and present estimates should be done very carefully since different methodology had been applied. So, the difference in estimates observed may or may not reflect the decreasing risk of trypanosomosis in Ethiopia [43].

The pooled prevalence estimate varies significantly between regions. High prevalence of bovine trypanosomosis was reported from Benishangul Gumuz regional state. The studies were conducted mainly in endemic areas for bovine trypanosomosis and non-endemic regions and remote regions may possibly be underrepresented. Even if the disease is known to be endemic to the Gambella Regional State, no study was reported from this region. Thus, the regional differences of data availability may have led to an over-estimation of the estimates for some regions. Due to the heterogeneous distribution of bovine trypanosomosis in Ethiopia, additional studies which are based on geostatistical techniques are needed. The studies must take into consideration distribution of tsetse and other biting flies, environmental factors, reservoir hosts, the control efforts made and settlement patterns.

Haematocrit centrifugation technique (HCT) was used in all the studies considered for the meta-analysis. Parasitological techniques like the HCT have been reported to be of low sensitivity but good specificity [44]. These 
techniques are of limited significance especially when parasitaemias are low as often observed in endemic areas [45]. According to Moti et al. [46], the percentage of positivity for the presence of trypanosomes detected by HCT was increased by more than 50 and $250 \%$ when using PCR-RFLP-fp and PCR-RFLP-pb, respectively. This confirms the considerable under-estimation of the prevalence in research results reported and used in this analysis. Therefore, the pooled prevalence of bovine trypanosomosis reported in the study might be significantly lower than the real situation.

The study has some limitations. First, data showed a large degree of heterogeneity among studies, which remained even after sub-group analysis. Therefore, the findings may not necessarily reflect the real situation of the entire country. Other limitations are a consequence of incomplete or inaccurate information provided in the publications. Despite a comprehensive search, it is likely that some studies conducted have not been found because they are not published in journals indexed by PubMed. Even if the test for publication bias is not significant, it is difficult to exclude it from the limitations. In addition, studies were conducted between 1997 and 2014. This long time period was necessary because of the limited availability of data, but limits interpretation to some degree.

In Ethiopia, T. congolense is considered to be the most important trypanosome species. In this study $T$. congolense and $T$. vivax were found to be the two most predominant trypanosome species. The burden of non tsetse transmitted trypanosomosis like trypanosomosis caused by $T$. vivax is being reported to be considerable [24]. According to Fikru et al. [24], the occurrence of mechanically transmitted trypanosomosis caused by $T$. vivax is very widespread than previously thought. The high prevalence of $T$. vivax most likely indicates the local transmission in the non-tsetse infested area by biting flies. It is indicated that $T$. vivax can adapt to a non-tsetse dependent transmission cycle [47]. As a consequence, the eradication of tsetse fly in Ethiopia, which is a core focus area of Pan African Tsetse and Trypanosomosis Eradication Campaign and other tsetse control initiatives, might have little effect on the prevalence of T. vivax.

\section{Conclusion}

To our knowledge, this is the first quantitative review attempt made on bovine trypanosomosis. The pooled bovine trypanosomosis prevalence estimate is high; however, higher degree of variability was observed between regions as well as survey year. The prevalence of the disease significantly reduces along time. The prevalence might be much higher if the studies used in the metaanalysis used highly sensitive molecular techniques. To this end, the use of molecular techniques for the diagnosis of bovine trypanosomosis should be adopted. T. vivax is reported to be one of the most important trypanosome species involved. Therefore, apart from the tsetse eradication campaign which is currently ongoing, efforts should also be made to control the mechanical transmission by biting flies such as tabanids, stomoxys and other potential mechanical vectors.

\section{Additional file}

Additional file 1: PRISMA Checklist. (XLSX 25 kb)

\section{Competing interests}

The authors declare that they have no competing interests.

\section{Authors' contributions}

SL conducted the analysis and developed the maps. All authors drafted the manuscript. All authors read and approved the final manuscript.

\section{Acknowledgement}

We thank Dao Ha Thi Thanh, PhD fellow at Institute of Tropical Medicine, for providing some of the literature.

\section{Author details}

${ }^{1}$ Faculty of Veterinary Medicine, University of Gondar, P.O. Box: 196, Gondar, Ethiopia. ${ }^{2}$ College of Veterinary Medicine, Samara University, Samara, Ethiopia.

Received: 30 January 2016 Accepted: 23 February 2016

Published online: 10 March 2016

\section{References}

1. Reid RS. Impacts of trypanosomosis on land-use and the environment in Africa: state of our knowledge and future directions. In proceeding of the 24th meetings of international scientific council for trypanosomiasis Research and control(ISCTRC). Maputo, Mozambique: OAU/ISTRC; 1997.

2. Mattioli RC, Slingenbergh J. ProgrammeAgainst African Trypanosomiasis (PAAT) Information System. http://www.fao.org/ag/AGAinfo/programmes/ en/paat/disease.html. 2013.

3. Swallow BM. Impact of Trypanosomiasis on African Agriculture. Vol. 2, PAAT Technical and Scientific Series, FAO.Rome. Int J Anim Veter Adv. 2000;2:47-50.

4. Omotainse SO, Kalejaiye JO, Dede P, Dada AJ. The current status of tsetse and animal trypanosomiasis in Nigeria. J Vet Sci. 2004;1:1-9.

5. Shaw AP, Cecchi G, Wint GR, Mattioli RC, Robinson TP. Mapping the economic benefits to livestock keepers from intervening against bovine trypanosomosis in Eastern Africa. Prev Vet Med. 2015;113:197-210.

6. Glass G. Primary, secondary and meta-analysis of research. Educ Res. 1976;5: 3-8.

7. Dohoo I, Martin W, Stryhn H. Veterinary Epidemiologic Research. 550 University Avenue, Charlottetown, Prince Edward Island, Canada: AVC Inc:; 2003.

8. Leandro G. Meta-analysis in medical research, the handbook for the understanding and practice of meta-analysis. 350 Main Street, Malden, Massachusetts 02148-5020, USA: Blackwell Publishing, Inc; 2005.

9. Moher D, Liberati A, Tetzlaff J, Altman DG, The PRISMA Group. Preferred reporting items for systematic reviews and meta-analyses: The PRISMA Statement. PLoS Med. 2009;6:e1000097.

10. FAO: Food and Agriculture Organization of the United Nations, FAOSTAT Database, Available at http://faostat3.fao.org/faostat-gateway/go/to/ download/O/OA/E. 2014.

11. Leta S, Mesele F. Spatial analysis of cattle and shoat population in Ethiopia: growth trend, distribution and market access. Springerplus. 2014;3:310.

12. Hedges LV, Vevea JL. Fixed- and random-effects models in meta-analysis. Psychol Methods. 1998;3:486-504.

13. Higgins JP, Thompson SG. Quantifying heterogeneity in a meta-analysis. Stat Med. 2002;21:1539-58. 
14. Egger M, Davey Smith G, Schneider M, Minder C. Bias in meta-analysis detected by a simple graphical test. BMJ. 1997;315:629-34.

15. Duval S, Tweedie R. Trim and fill: a simple funnel-plot-based method of testing and adjusting for publication bias in meta-analysis. Biometrics. 2000;56:455-63.

16. Abera Z, Fekadu M, Kabeta T, Kebede G, Mersha T. Prevalence of Bovine Trypanosomosis in Bako Tibe District of West Shoa and Gobu Seyo Districts of West Wollega Zone, Ethiopia. Eur J Biol Sci. 2014;6(3):71-80.

17. Afewerk Y, Clausen PH, Abebe G, Tilahun G, Mehlitz D. Multiple-drug resistant Trypanosoma congolense populations in village cattle of Metekel district, north-west Ethiopia. Acta Trop. 2000;76:231-8.

18. Bekele M, Nasir M. Prevalence and host related risk factors of bovine trypanosomosis in Hawagelan district, West Wellega zone, Western Ethiopia. Afr J Agr Res. 2011;6(22):5055-60.

19. Birhanu H, Fikru R, Said M, Kidane W, Gebrehiwot T, Hagos A, Alemu T, Dawit T, Berkvens D, Goddeeris BM, Buscher P. Epidemiology of Trypanosoma evansi and Trypanosoma vivax in domestic animals from selected districts of Tigray and Afar regions, Northern Ethiopia. Parasit Vectors. 2015;8:212-30.

20. Bishaw $Y$, Temesgen W, Yideg N, Alemu S. Prevalence of bovine trypanosomosis in Wemberma district of West Gojjam zone, North West Ethiopia. Ethiop Vet J. 2012;16(2):41-8.

21. Biyazen H, Duguma R, Asaye M. Trypanosomosis, Its Risk Factors, and Anaemia in Cattle Population of Dale Wabera District of Kellem Wollega Zone, Western Ethiopia. J Vet Med. 2014;2014:374191.

22. Cherenet T, Sani RA, Panandam JM, Nadzr S, Speybroeck N, Van den Bossche P. Seasonal prevalence of bovine trypanosomosis in a tsetseinfested zone and a tsetse-free zone of the Amhara Region, north-west Ethiopia. Onderstepoort J Vet Res. 2004;71:307-12.

23. Dagnachew S, Shibeshi S. Prevalence and vector distributions of bovine trypanosomosis in control (Sibu Sire) and noncontrol (Guto Gida) districts bordering upper Anger valley of East Wollega Zone, Western Ethiopia. Ethiop Vet J. 2011;15(2):77-86.

24. Fikru R, Goddeeris BM, Delespaux V, Moti Y, Tadesse A, Bekana M, Claes F, De DR, Buscher P. Widespread occurrence of Trypanosoma vivax in bovines of tsetse- as well as non-tsetse-infested regions of Ethiopia: a reason for concern? Vet Parasitol. 2012:190:355-61.

25. Kebede N, Fetene T, Animut A. Prevalence of Trypanosomosis of small ruminants in Guangua district of Awi Zone, northwestern Ethiopia. J Infect Dev Ctries. 2009;3:245-6.

26. Kidanemariam A, Hadgu K, Sahle M. Parasitological prevalence of bovine trypanosomosis in Kindo Koisha district, Wollaita zone, south Ethiopia. Onderstepoort J Vet Res. 2002;69(2):107-13.

27. Lelisa K, Shimeles S, Bekele J, Sheferaw D. Bovine trypanosomosis and its fly vectors in three selected settlement areas of Hawa-Gelan district, western Ethiopia. Onderstepoort J Vet Res. 2014;81.

28. Lelisa K, Damena D, Kedir M, Feyera T. Prevalence of bovine trypanosomosis and apparent density of tsetse and other biting flies in Mandura District, Northwest Ethiopia. J Vet Sci Technolo. 2015;6(3):6

29. Mekuria S, Gadissa F. Survey on bovine trypanosomosis and its vector in Metekel and Awi zones of Northwest Ethiopia. Acta Trop. 2011;117:146-51.

30. Mihret A, Mamo G. Bovine trypanosomosis in three districts of East Gojjam Zone bordering the Blue Nile River in Ethiopia. J Infect Dev Ctries. 2007;1:321-5.

31. Miruk A, Hagos A, Yacob HT, Asnake F, Basu AK. Prevalence of bovine trypanosomosis and trypanocidal drug sensitivity studies on Trypanosoma congolense in Wolyta and Dawero zones of southern Ethiopia. Vet Parasitol. 2008; 152:141-7.

32. Sheferaw D, Birhanu B, Asrade B, Abera M, Tusse T, Fikadu A, Denbarga Y, Gona Z, Regassa A, Moje N, Kussito E, Mekibib B, Asefa T, Woldesenbet Z. Bovine trypanosomosis and glossina distribution in selected areas of southern part of Rift Valley, Ethiopia. Acta Trop. 2015;154:145-148.

33. Tadesse A, Tsegaye B. Bovine trypanosomosis and its vectors in two districts of Bench Maji zone, South Western Ethiopia. Trop Anim Health Prod. 2010;42:1757-62

34. Tafese W, Melaku A, Fentahun T. Prevalence of bovine trypanosomosis and its vectors in two districts of East Wollega Zone, Ethiopia. Onderstepoort J Vet Res. 2012;79:E1-4.

35. Tamiru F, Mideksa B, Roy RK, Terfa W. Post Control Survey on Prevalence of Bovine Trypanosomosis and Vector Distribution in Ameya District, South West Shewa, Ethiopia. Glob J Med Res k. 2014;14(3).

36. Terefe E, Haile A, Mulatu W, Dessie T, Mwai O. Phenotypic characteristics and trypanosome prevalence of Mursi cattle breed in the Bodi and Mursi districts of South Omo Zone, southwest Ethiopia. Trop Anim Health Prod. 2015:47:485-93.

37. Tesfaye D, Speybroeck N, De DR, Thys E. Economic burden of bovine trypanosomosis in three villages of Metekel zone, northwest Ethiopia. Trop Anim Health Prod. 2012;44:873-9.

38. Tewelde N, Abebe G, Eisler M, McDermott J, Greiner M, Afework Y, Kyule M, Munstermann S, Zessin KH, Clausen PH. Application of field methods to assess isometamidium resistance of trypanosomes in cattle in western Ethiopia. Acta Trop. 2004;90:163-70.

39. Kebede N, Animut A. Trypanosomosis of cattle in selected districts of Awi zone, northwestern Ethiopia62. Trop Anim Health Prod. 2009:41:1353-6.

40. Gechere G, Terefe G, Belihu K. Impact of tsetse and trypanosomiasis control on cattle herd composition and calf growth and mortality at Arbaminch District (Southern Rift Valley, Ethiopia). Trop Anim Health Prod. 2012;44(7): 1745-50.

41. Balis J, Bergeon P. A study on the distribution of tsetse flies in Ethiopia. Bull World Health Organ. 1968;38:809-13.

42. Balis J, Bergeon P. Brief study of Glossina distribution in the Ethiopian empire. Rev Elev Med Vet Pays Trop. 1970;23:181-7.

43. Leta S, Habtamu Y, Alemayehu G, Chanie M, Ayele B, Tesfaye S, Mesele F. Spatial analysis of the distribution of tsetse flies in Ethiopia using high resolution environmental datasets and Maxent modeling technique. In National Syposium on Trends and challenges in Adoption of Science, Technology and Innovation in Local Development Endeavours, Nekemte, Ethiopia: Wollega University; 2015.

44. Gardiner PR. Recent studies of the biology of Trypanosoma vivax. Adv Parasitol. 1989;28:229-317

45. Desquesnes M. Evaluation of a simple PCR technique for the diagnosis of Trypanosoma vivax infection in the serum of cattle in comparison to parasitological techniques and antigen-enzyme-linked immuno sorbent assay. Acta Trop. 1997;65:139-48.

46. Moti Y, Fikru R, Buscher P, Van Den Abbeele J, Duchateau L, Delespaux V. Detection of African animal trypanosomes: the haematocrit centrifugation technique compared to PCR with samples stored on filter paper or in DNA protecting buffer. Vet Parasitol. 2014:203:253-8.

47. Davila AM, Silva RA. Animal trypanosomiasis in South America. Current status, partnership, and information technology. Ann N Y Acad Sci. 2000;916:199-212.

48. Sinshaw A, Abebe G, Desquesnes M, Yoni W: Biting flies and Trypanosoma vivax infection in three highland districts bordering lake Tana, Ethiopia. Vet Parasitol. 2006;142(1-2):35-46.

\section{Submit your next manuscript to BioMed Central and we will help you at every step:}

- We accept pre-submission inquiries

- Our selector tool helps you to find the most relevant journal

- We provide round the clock customer support

- Convenient online submission

- Thorough peer review

- Inclusion in PubMed and all major indexing services

- Maximum visibility for your research

Submit your manuscript at www.biomedcentral.com/submit 